\title{
Influence of osteogenic stimulation and VEGF treatment on in vivo bone formation in hMSC-seeded cancellous bone scaffolds
}

\author{
Ulrich Lenze ${ }^{1,2 \dagger}$, Florian Pohlig ${ }^{1,2,3 \dagger}$, Sebastian Seitz ${ }^{4}$, Christina Ern ${ }^{1,5}$, Stefan Milz ${ }^{6}$, Denitsa Docheva ${ }^{{ }^{*}}$
} and Matthias Schieker ${ }^{1}$

\begin{abstract}
Background: Tissue engineering approaches for reconstruction of large bone defects are still technically immature, especially in regard to sufficient blood supply. Therefore, the aim of the present study was to investigate the influence of osteogenic stimulation and treatment with VEGF on new bone formation and neovascularization in hMSC-loaded cancellous bone scaffolds in vivo.

Methods: Cubic scaffolds were seeded with hMSC and either cultured in stem cell medium or osteogenic stimulation medium. One osteogenically stimulated group was additionally treated with $0.8 \mu \mathrm{g}$ VEGF prior to subcutaneous implantation in athymic mice. After 2 and 12 weeks in vivo, constructs and selected organs were harvested for histological and molecular analysis.

Results: Histological analysis revealed similar vascularization of the constructs with and without VEGF treatment and absence of new bone formation in any group. Human DNA was detected in all inoculated scaffolds, but a significant decrease in cells was observed after 2 weeks with no further decrease after 12 weeks in vivo.
\end{abstract}

Conclusion: Under the chosen conditions, osteogenic stimulation and treatment with VEGF does not have any influence on the new bone formation and neovascularization in hMSC-seeded cancellous bone scaffolds.

Keywords: hMSC, Tissue engineering, VEGF, Vascularization, Osteogenic stimulation

\section{Background}

Large bone defects caused by trauma, tumor or infection still represent a major problem in reconstructive surgery. Tissue engineering approaches for reconstruction of such bone defects are appealing, but to date technically insufficient. In this context, one major problem - the blood supply during the first days in vivo - remains unsolved. Since the rate of vessel ingrowth into a cell-loaded scaffold is hypothesized to be less than one millimeter per day, a considerable period is needed to provide sufficient blood supply and delivery of substrates such as glucose and oxygen to inner parts of the engineered scaffold [1,2]. Likewise, removal of waste products such as carbon dioxide

\footnotetext{
* Correspondence: denitsa.docheva@med.uni-muenchen.de

${ }^{\dagger}$ Equal contributors

'Laboratory of Experimental Surgery and Regenerative Medicine, Department of Surgery, University of Munich (LMU), Munich, Germany

Full list of author information is available at the end of the article
}

and lactate via the bloodstream is delayed until a mature vascular system is established. Since bone represents a metabolically active tissue, the insufficient blood supply during the first days in vivo might compromise cell survival and hence lead to failure of the graft integration [2]. Therefore, various tissue engineering strategies have been developed to address this problem.

One promising approach is the use of growth factors such as vascular endothelial growth factor (VEGF), which plays an important role in inducing neovascularization and bone healing [3]. Kaigler et al. reported on significantly increased vascular perfusion and bone formation in irradiated osseous defects using VEGF-releasing polymer scaffolds [4]. Beside the improved blood supply, this phenomenon could also be ascribed to the VEGF-triggered bilateral communication between endothelial and osteogenic cell lineages leading to a broad proliferation of endothelial cells and 
differentiation of osteogenic progenitor cells into osteoblasts $[5,6]$.

The ability of hMSCs for differentiation along several cell lineages is well known and depends on the tissue source, whereas a substantial loss of their multi-potent properties was observed during culture in vitro [7]. Although many preclinical animal models showed ectopic as well as orthotopic bone formation following implantation of 3D cell-loaded constructs, questions regarding the optimal osteogenic differentiation method for hMSCs as well as an effective initiation of osteogenesis in vivo have not been finally clarified.

Therefore, the aim of this study was to determine if VEGF treatment of osteogenically stimulated hMSCs loaded on cancellous bone scaffolds is capable of enhancing neovascularization and bone formation in an ectopic mouse model.

\section{Methods}

\section{Scaffold loading and cultivation of human mesenchymal} stem cells

Human mesenchymal stem cells (hMSC) (Cambrex, East Rutherford, USA), which were harvested and purified from bone marrow aspirates of one healthy donor were purchased (Lonza, Basel, Switzerland) and cultivated in mesenchymal stem cell growth medium (MSCGM) (Lonza, Basel, Switzerland). Fresh medium was supplied three times per week. When cell layers neared confluence, cells were detached using trypsinEDTA. Cultures were maintained in a humidified atmosphere of $95 \%$ air with $5 \% \mathrm{CO}_{2}$ at $37^{\circ} \mathrm{C}$.

The day before loading, cubic solvent-preserved and irradiated bovine cancellous bone scaffolds (Tutobone, Tutogen Medical, Neunkirchen am Brand, Germany) with an edge length of $3 \mathrm{~mm}$ were preincubated for 24 hours in MSCGM [8]. A suspension of $1.1 \times 10^{6} \mathrm{hMSCs}$ (passage 4) in $660 \mu \mathrm{l}$ medium was evenly applied to each scaffold. For maximum seeding efficiency, scaffolds were turned and the cell suspension was resuspended onto each construct every 20 minutes. After 6 hours, all scaffolds were transferred to well-plates for further incubation. The seeding efficiency was assessed by measuring the number of remaining cells within the supernatant suspension in each well.

Following seeding, the scaffolds were cultured for 14 days either in MSCGM or in case of osteogenic stimulation in Dulbecco's Modified Eagle Medium (DMEM, Gibco, Invitrogen, Carlsbad, USA) containing 10\% fetal bovine serum (FBS, Sigma-Aldrich, St. Louis, USA),

$4 \mathrm{mM}$ L-Glutamine, $100 \mathrm{nM}$ Dexamethasone, $10 \mathrm{mM}$ b-Glycerophosphate and $50 \mathrm{mM} \mathrm{L-Ascorbic} \mathrm{acid} \mathrm{2-}$ phosphate. Medium was changed every second day throughout the entire culture period. Directly before subcutaneous implantation, 6 osteogenically stimulated cellloaded scaffolds were additionally injected with $0.8 \mu \mathrm{g}$ human VEGF (Peprotech, Rocky Hill, USA).

\section{Experimental design and surgical procedure}

In total 12 athymic nude mice ranging from six to eight weeks of age (nu/nu, Harlan Winkelmann, Rossdorf, Germany) with a live weight of 25-30 g were used for this study. Following intramuscular anaesthesia using a fentanyl-medetomidin-midazolam mixture $(0,625 \mathrm{mg}$ fetanyl, 0,125 mg medetomidin and 6,25 mg midazolam per kilogramm body weight), two subcutaneous paravertebral pouches were prepared by a blunt dissection. Within the first experimental setup, unstimulated empty scaffolds ( $n=6$, group 1$)$ were implanted left paravertebrally, whereas scaffolds seeded with hMSCs $(n=6$, group 2) were implanted on the right side. Scaffolds seeded with osteogenically stimulated hMSCs $(n=6$, group 3 ) as well as an additional VEGF treatment ( $\mathrm{n}=6$, group 4) were implanted in a second series paravertebrally to the right and left, respectively (Figure 1a). After implantation, pouches were sutured in order to prevent contact between implanted constructs.

After 2 and 12 weeks, scaffolds were harvested including the surrounding tissue. One scaffold of each group was split into two parts; one half destined for decalcification was fixed in $100 \%$ methanol, while the other was put into a formaldehyde/methanol solution (formaldehyde 35\%, methanol $100 \%$, isotonic glucose $1 \%$ and phosphate buffer), both for $48 \mathrm{~h}$ (Figure 1b). The other scaffold of each group was shock frozen in fluid nitrogen and stored at $-80^{\circ} \mathrm{C}$ until used for molecular analysis (Figure 1b). In addition, selected organs (blood, brain, heart, lung, liver, kidneys, spleen, testes, scaffold surrounding skin and muscle tissue) were harvested, snap frozen in liquid nitrogen and stored at $-80^{\circ} \mathrm{C}$ until further use.

This study adhered to the ARRIVE guidelines, was approved by the "Government of Upper Bavaria" and all animals were handled according to the LMU guidelines (Ludwig-Maximilians-University of Munich) for the care and use of laboratory animals.

\section{Histological analysis}

Scaffolds fixed in the formaldehyde/methanol solution were dehydrated in a graded series of ethanol over 5 days and afterwards embedded into methyl methacrylate (MMA). Next, $4 \mu \mathrm{m}$ thick sections were collected from each scaffold by using a Polycut microtome (Reichert-Jung, Heidelberg, Germany). Sections were stained with Goldner's Trichrome and Toluidine Blue.

Scaffolds fixed in methanol were decalcified with 5\% EDTA/PBS solution over 4 weeks. The solution was changed every third day. Sections of $12 \mu \mathrm{m}$ thickness were obtained by using a cryomicrotome (Microm, Walldorf, Germany) and then stained with Hematoxylin and Eosine.

All sections were investigated using a light microscope (Axioskop, Zeiss, Jena, Germany) and graded by 3 independent observers for the presence and extent of: i) 


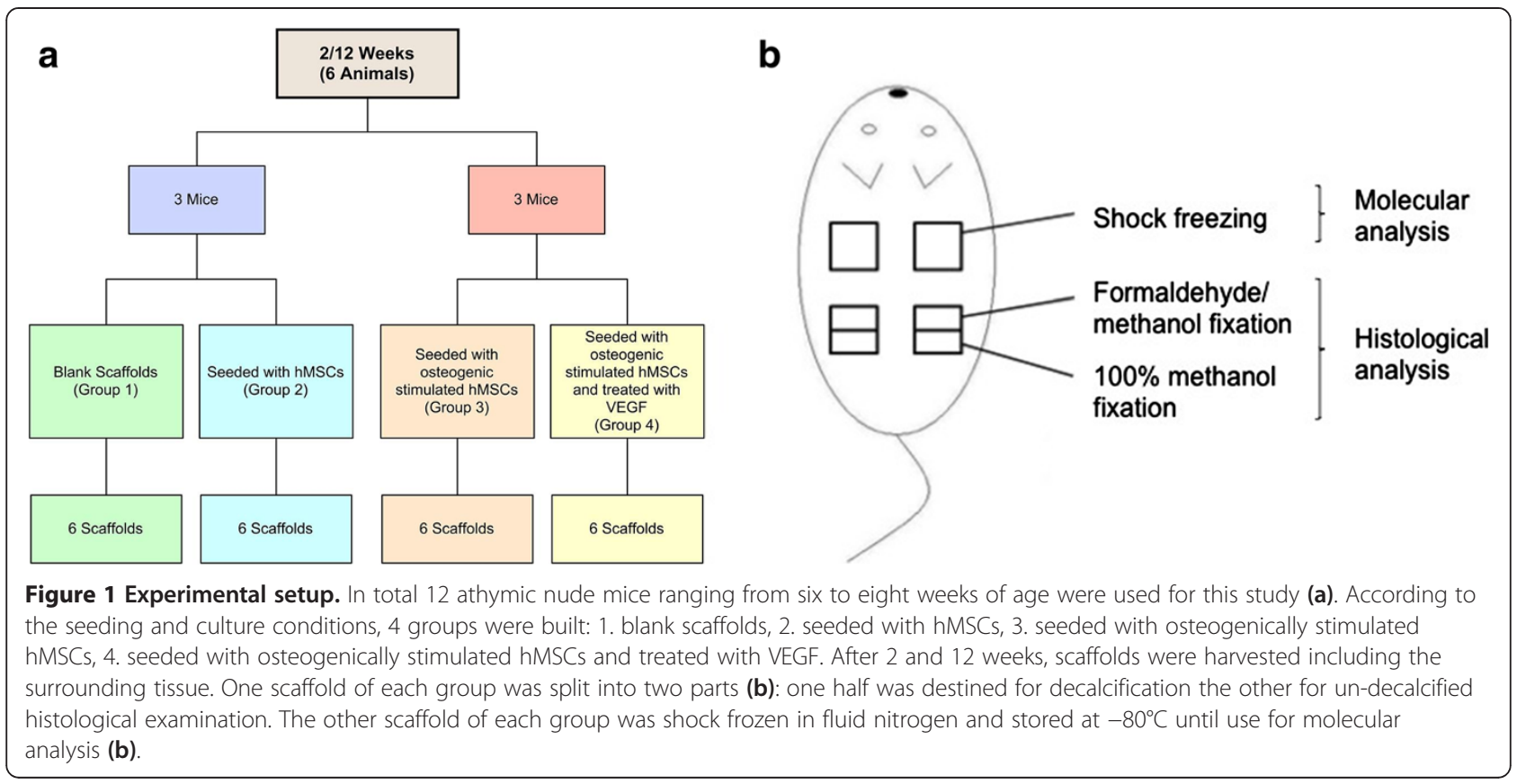

granulation tissue, ii) necrosis, iii) fat cells, iv) neovascularization and v) foreign body giant cells. The grading scale ranged from 1 (tissue extent 1-20\% of the scaffold/ single cells in the border areas) to 5 (tissue extent 80$100 \% /$ lots of cells in all areas) according to the established method by van Gaalen [9].

\section{Extraction of genomic DNA}

The isolation of DNA from the scaffolds was performed with DNeasy blood and tissue kit (Qiagen, Hilden, Germany) according to the manufacturer's instructions. In brief, harvested tissue samples were lysed with proteinase $\mathrm{K}(>600 \mathrm{mAU} / \mathrm{ml})$. The DNA in the lysed samples was then absorbed on a silica matrix and cell debris was removed by washing with DNeasy washing buffer. Finally, the DNA was collected by elution in AE buffer (Qiagen, Hilden, Germany) and photometrically quantified.

\section{Semiquantitative polymerase chain reaction (PCR)}

Detection of human DNA within the scaffolds and various organs was performed by genomic PCR. An 850 bp fragment of the $\alpha$-satellite region of the human chromosome 17 was amplified using primers as previously described in Becker et al. [10].

Each PCR reaction (end volume of $50 \mu \mathrm{l}$ ) contained $250 \mathrm{ng}$ of human genomic DNA, $200 \mu \mathrm{M}$ of nucleotide mixture, $250 \mu \mathrm{M}$ of each primer, $2.5 \mathrm{U}$ Taq Polymerase and Q-solution (Qiagen, Hilden, Germany) supplemented with $15 \mathrm{nM} \mathrm{MgCl}_{2}$.

An initial denaturation of $3 \mathrm{~min}$. at $94^{\circ} \mathrm{C}$ was followed by 40 cycles comprised of $30 \mathrm{sec}$. at $94^{\circ} \mathrm{C}$, annealing at $58^{\circ} \mathrm{C}$ for $1 \mathrm{~min}$. and for another $1 \mathrm{~min}$. a polymerase reaction at $72^{\circ} \mathrm{C}$. Finally, 10 minutes of polymerisation and an interruption of the reaction by cooling down to $4^{\circ} \mathrm{C}$ completed the cycles. Amplified DNA fragments (850 bp) were transferred onto 1.75\% agarose gels and after the electrophoresis, they were stained with ethidium bromide and analysed using ultraviolet light.

Isolated DNA from hMSCs served as positive control while DNA extracted from murine fibroblasts served as negative control in each PCR run. To prove the PCR sensitivity, genomic DNA mixture containing DNA from murine fibroblasts and hMSCs in different ratios $\left(1 \times 10^{6}\right.$ murine fibroblasts $+10 \mathrm{hMSCs}$ and $1 \times 10^{6}$ mouse fibroblasts $+1 \mathrm{hMSC}$ ) was also used in each PCR run.

\section{Quantitative PCR}

Quantitative PCR was performed by using LightCycler technology (Roche, Mannheim, Germany). A specific human primer set was purchased from Search-LC (Search-LC, Heidelberg, Germany). The final volume of each PCR-reaction was $20 \mu \mathrm{l}$ containing $10 \mu \mathrm{l}$ of $5 \mathrm{ng}$ genomic DNA, $10 \mu \mathrm{l}$ of a PCR-Mix $(6 \mu \mathrm{l}$ PCR grade water, $2 \mu \mathrm{l}$ of primers and $2 \mu \mathrm{l}$ of LightCycler Fast Start Master SYBR Green I; Roche).

Each PCR cycle consisted of a 10 second denaturation at $95^{\circ} \mathrm{C}$ followed by annealing at $68^{\circ} \mathrm{C}$ for $10 \mathrm{sec}$. with a transition to $58^{\circ} \mathrm{C}$ in steps of $0.5^{\circ} \mathrm{C}$ per cycle. Elongation was performed at $72^{\circ} \mathrm{C}$ for 16 seconds during which fluorescence intensity was measured in each cycle. The temperature transition rate of all steps was $20^{\circ} \mathrm{C}$ per second. Serial dilution steps of human genomic DNA in $10 \mu \mathrm{l}$ distilled water (60 ng, 6 ng, 0.6 ng, 0.06 ng, 0.006 ng, 0.0006 ng DNA) were used to generate standard curves. In every PCR, DNA 
from hMSCs was used as a positive control, while DNA from murine fibroblasts served as a negative control.

Finally, the number of cells on the scaffold after explantation was calculated by the measured amount of human DNA and the common presumption of a genomic DNA content of $6 \mathrm{pg}$ in eukaryotic cells.

\section{Statistical analysis}

Comparison analysis was performed with the quantitative PCR data using SPSS software (IBM, Armonk, USA) and the unpaired $t$-test. The results are shown as mean \pm standard deviation. A p-value of $\leq 0.05$ was considered statistically significant.

\section{Results}

\section{Seeding efficiency}

From the original amount of $1.1 \times 10^{6} \mathrm{hMSCs}$ applied onto the scaffolds, a mean of $7.1 \times 10^{5}$ cells (median $7.0 \times 10^{5}$ cells, range $4.1 \times 10^{5}-9.1 \times 10^{5}$ cells) adhered to the scaffold (Figure 2). The mean seeding efficiency of all scaffolds was $64.8 \%$ (median $64.1 \%$, range $41.7 \%-83.3 \%$ ). The statistical evaluation of seeding efficiencies did not show significant differences between the four experimental groups.

\section{Animal experiments}

All animals showed good general conditions, dry wounds with no sign of irritation as well as appropriate behavior at the time of explantation. No animals died or suffered from diseases during the whole study duration prior to euthanasia.

\section{Histological findings}

After an implantation period of 2 weeks, an incipient ingrowth of fibrous- and granulation tissue as well as small vessels was observed in each scaffold. In all groups (1. unstimulated empty scaffolds, 2. inoculated with hMSCs, 3. inoculated with osteogenic stimulated hMSCs, 4. inoculated with osteogenically stimulated hMSCs and treated

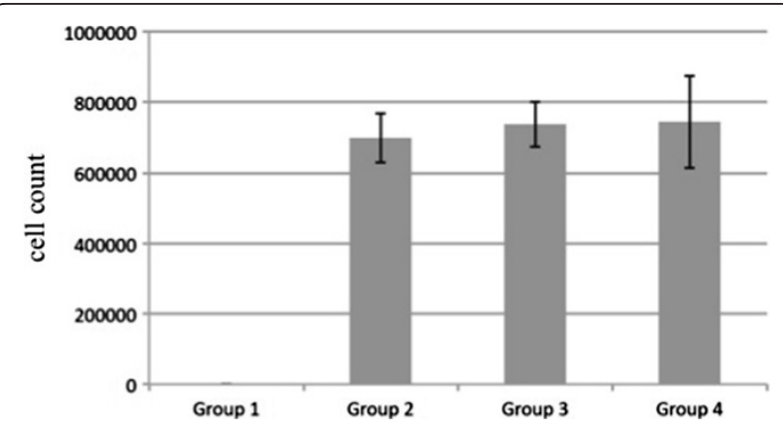

Figure 2 Cell count after scaffold seeding with hMSCs. From the original amount of $1.1 \times 10^{6} \mathrm{hMSC}$, a mean of $7.1 \times 10^{5}$ cells adhered to the scaffold. Group 1: blank scaffolds (control); Group 2: seeded with hMSCs; Group 3: seeded with osteogenically stimulated hMSCs; Group 4: seeded with osteogenically stimulated hMSCs and treated with VEGF. with VEGF), newly formed capillaries and small vessels were detected, lying evenly distributed mainly in the outer regions of the scaffold (Figure 3). Granulation tissue was also observed in all groups (Figure 4). Inner parts of the constructs contained scattered fat cells, inflammatory cells, and sometimes necrotic areas. Multinucleated giant cells were found in scaffolds from all groups. These cells were mostly aligned in groups of $2-4$ along the edge of the scaffolds. Fat cells were observed within loose fibrous tissue, especially in outlying areas covering more than $20 \%$ of the scaffold surface. No apparent differences in the occurrence and distribution of necrotic areas were detected. Newly formed osteoid, bone- or cartilage tissue was not apparent after an implantation period of 2 weeks.

In the 12 weeks group, further ingrowth of the surrounding tissue into the constructs occurred. Especially, a change in the vascularization and the appearance of bigger fat cell aggregations was noticeable in all scaffolds (Figure 5). Compared to the histological results after 2 weeks of implantation, a clear increase in size and amount of vessels was detected after 12 weeks in all groups. Capillaries, venules and arterioles were evenly distributed over all parts of the scaffolds. Furthermore, an increased expansion of fat cells was found in all groups, covering up to $60 \%$ of the scaffold surface in some cases (Figure 6). The highest extent of fatty tissue was observed in unstimulated empty (group 1) and inoculated scaffolds (group 2), while the lowest extent was found in osteogenically stimulated constructs (group 3). Next to the fatty tissue, flanking necrotic areas were detected. Multinucleated giant cells showed an inhomogeneous distribution pattern and were found in the scaffold periphery but also in central areas. After an implantation period of 12 weeks, neither newly formed osteoid nor bone or cartilage tissue was obtained.

No differences regarding vascularization or tissue reaction and formation were observed between the groups independent from the different culture and stimulation conditions.

\section{Semi-quantitative PCR}

Human DNA was found in all inoculated scaffolds after explantation at both points in time. In blank scaffolds, no human DNA was detected. Moreover, we did not detect human DNA in any of the explanted organs as well as in the soft tissue surrounding the implanted scaffolds. Cell suspensions with hMSCs and murine cells served as controls allowing a detection of even $1 \mathrm{hMSC}$ in $10^{6}$ murine cells.

\section{Quantitative PCR}

With real time PCR, a significant decrease $(p<0.001)$ of human DNA and accordingly the directly proportional cell numbers on all cell-seeded constructs ( 2 and 12 weeks in vivo) could be measured compared to the amount of initially seeded cells (Figure 7). After 12 weeks, a further 


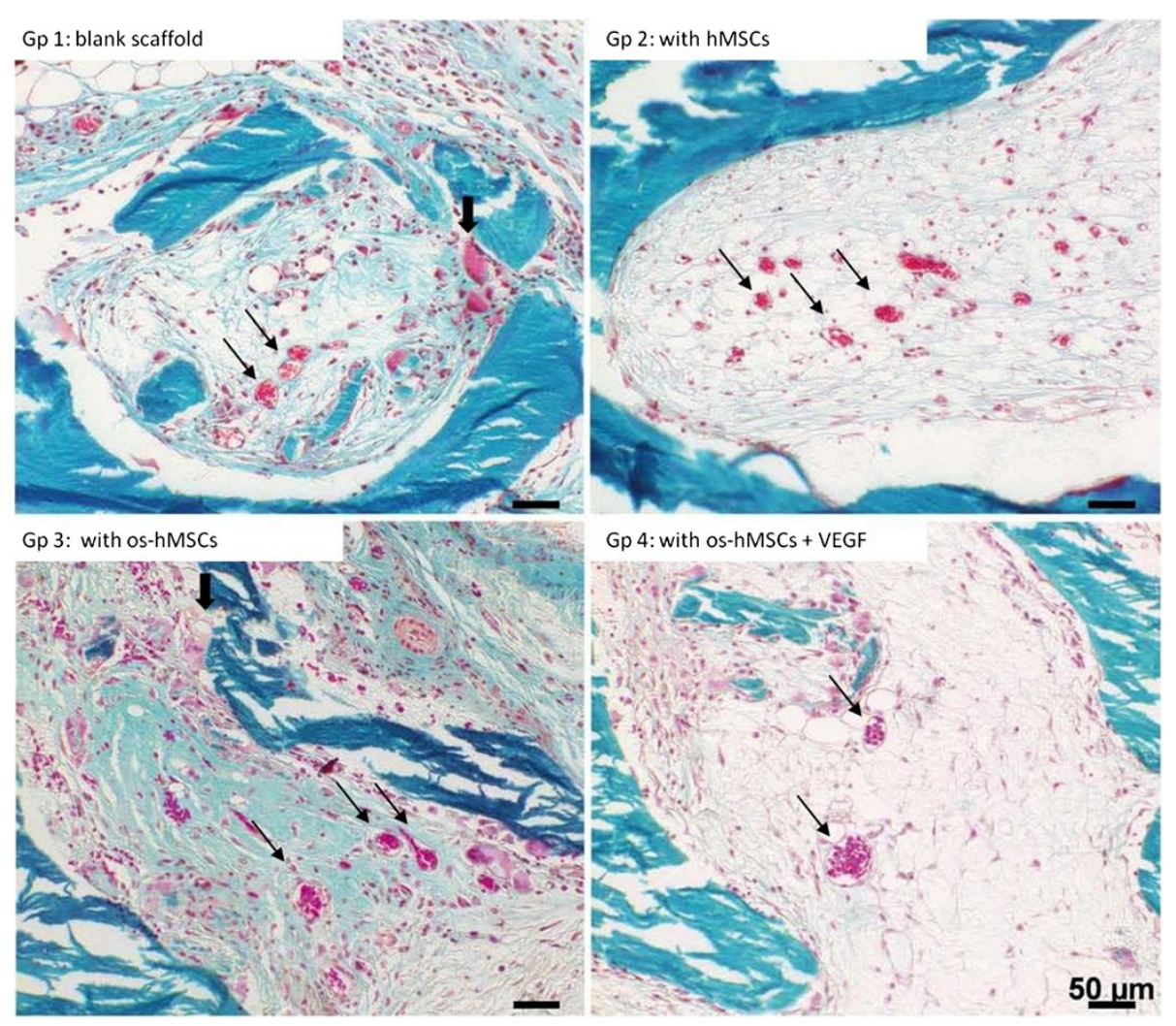

Figure 3 Vascularization after 2 weeks. Capillaries and small vessels (thin arrows) were detected in all groups after 2 weeks of in vivo implantation. In addition, multinucleated giant cells were observed on the scaffold surface (thick arrows). [Gp = Group, os-hMSCs= osteogenically stimulated hMSCs] Goldner's trichrome: scale bars: 50 ums.

decrease was detected in group 2 (inoculated) and 4 (inoculated with osteogenically stimulated hMSCs and VEGF treatment). Only for group 3 (seeded with osteogenically stimulated hMSCs), a slight increase of the cell number was observed after 12 weeks compared to 2 weeks (Figure 8). We identified higher cell numbers in the scaffolds with additional VEGF (group 4) after 2 weeks in comparison to just osteogenically stimulated scaffolds (group 3). After an implantation time of 12 weeks, group 4 showed inferior cell numbers. However, the abovementioned differences were statistically not significant.

\section{Discussion}

In this study, we aimed to evaluate the influence of osteogenic stimulation and application of vascular endothelial growth factor (VEGF) on bone formation in hMSC-seeded cancellous bone scaffolds after 2 and 12 weeks of subcutaneous implantation. During the implantation period, an ingrowth of surrounding host tissue was observed in all groups. Migration of human cells to host organs after xenogenic implantation was not seen in any of the animals, thus confirming previous results of our group [8]. Human DNA was detected in explanted scaffolds at all points in time, but a significant decrease in cells within the scaffolds could be measured in vivo compared to the amount of initially seeded cells. Neither bone formation nor higher amounts of neovascularization was observed. According to the journal guidelines ARRIVE check list for this study has been provided as Additional file 1.

\section{hMSC cultivation}

The high amount of mesenchymal stem cells (hMSCs) within the commercially available cells used in this study was proven and described previously [11]. However, authors reporting on successful in vivo regeneration of bone often used BMSCs (Bone Marrow Stroma Cells) gained from bone marrow containing quantitatively more pre-differentiated progenitor cells than hMSCs $[12,13]$. The presence of such progenitor cells, which can be expanded in vitro by osteogenic stimulation, is crucial for ectopic bone formation [14,15]. In this context, additional contribution of BMP-2 and FGF-2 should be taken into account since an increased osteoblastic differentiation in vitro might have positive effects on ectopic bone formation in vivo [16].

The lack of newly formed bone could also be attributed to the static cultivation procedure. Since an ideal nutrient supply plays a major role during the initiation and 

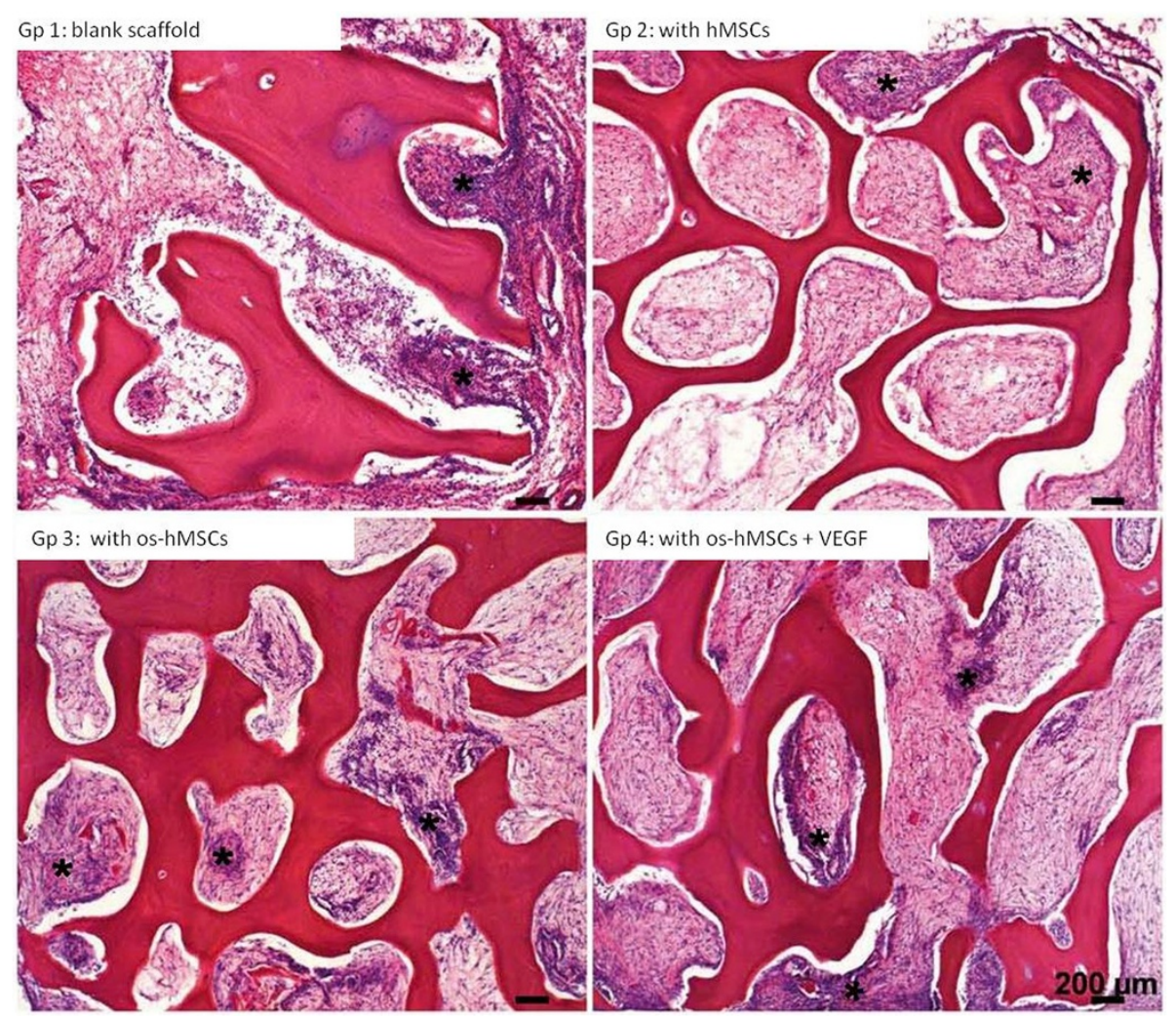

Figure 4 Tissue after 2 weeks. Granulation tissue $\left(^{*}\right)$ was observed in all groups after 2 weeks in vivo. [Gp = Group, os-hMSCs = osteogenically stimulated hMSCs] Hematoxylin-Eosin: scale bars: $200 \mu \mathrm{ms}$.

maintenance of cell differentiation processes in vitro, a dynamic cultivation could be beneficial. Dynamic compared to static cultivation of osteogenically stimulated cell matrix constructs was shown to enhance the formation of an extracellular matrix in vitro which facilitates more new bone formation in vivo [17]. Additionally, the differentiation of osteogenically stimulated cells along the osteoblastic cascade is positively influenced by cytomechanical forces actuated within dynamic culture tanks [18]. In this context, various methods to stimulate cells with mechanical forces were reported including tensile stress, compressive stress, shear stress, vibration and magnetic stimuli [19].

A decrease of oxygen concentration towards the center of the scaffold was shown under static cultivation, whereas the oxygen concentration of dynamically cultured constructs did not fall below $4 \%$ after 5 days [20]. These data reinforce the assumption that a considerable number of cells probably died during static cultivation in vitro due to a decreasing oxygen gradient towards the inner parts of the construct. This could be one reason for our results which show a significant decrease of cell numbers after 2 weeks in vivo but no further significant decrease after 12 weeks.

\section{Vasculature}

Taking into consideration that capillaries were predominantly located in the outer scaffold areas after 2 weeks in vivo, a further reason for the considerable decrease of hMSCs might be the lack of a sufficient vascular supply [8]. In our opinion, physical prerequisites regarding the diffusion threshold of $200 \mu \mathrm{m}-3.5 \mathrm{~mm}$ were met by the use of small cubic scaffolds with an edge length of $3 \mathrm{~mm}$ $[21,22]$. However, considering the obtained results, cell death must be assumed at least for inner cell layers within the scaffold. Likewise, Potier et al. reported on broad cell death in vitro after a maximum of 5 days when the cells were exposed to hypoxia and deprivation of serum [23]. In contrast, maintaining constant or preconditioning levels of hypoxia was shown to improve the osteogenic potential of hMSCs and possibly preserve the stem cell character of hMSCs in vitro [24]. The fact that even in the VEGF group sufficient vascular supply was not initiated and cell survival was not achieved could be attributed to the biological instability of VEGF in vivo as well as the short stimulation time [3]. This shortcoming could be overcome by the use of novel scaffolds binding VEGF by heparin crosslinking and thus, achieving localized and sustained delivery of this growth 

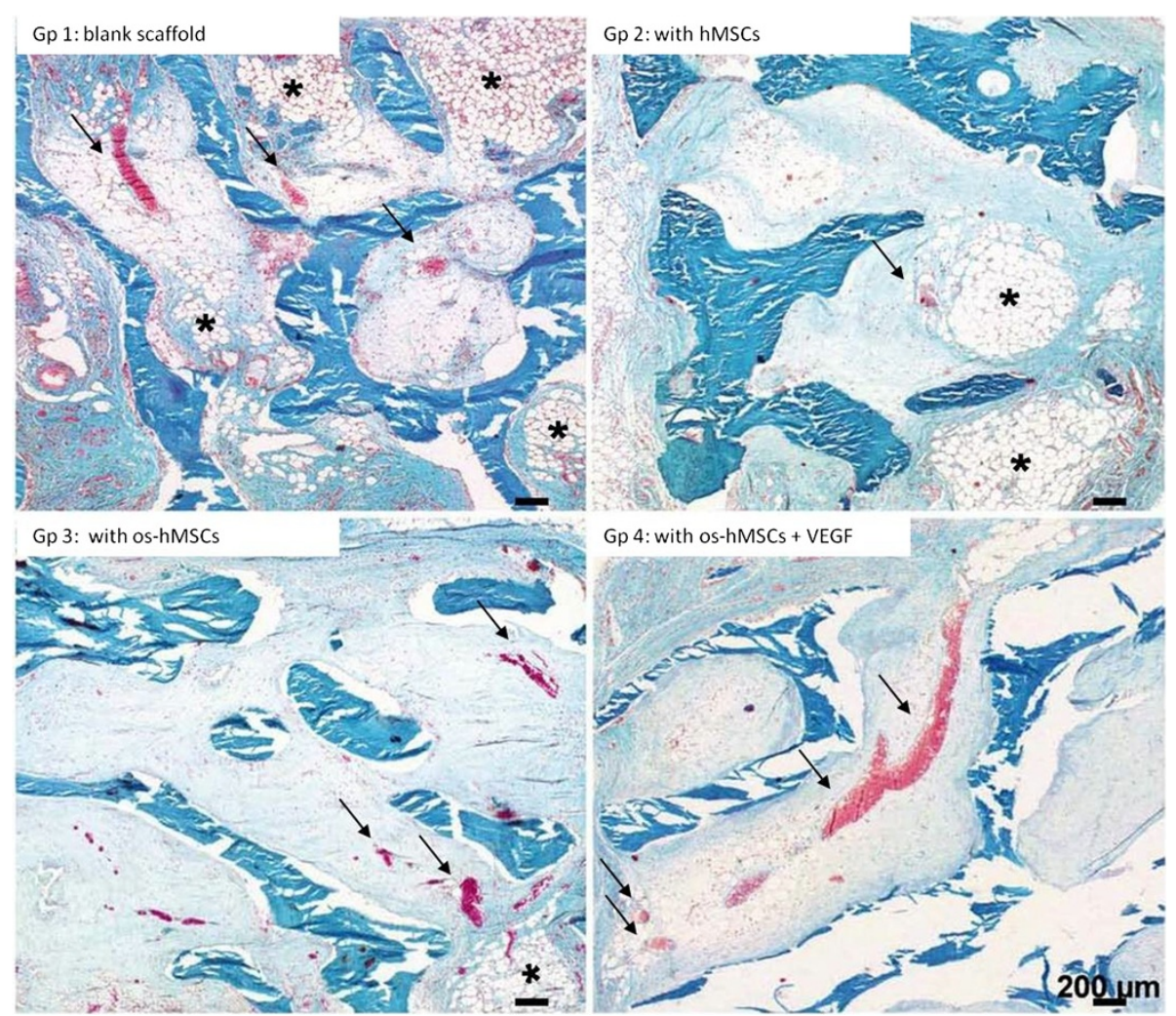

Figure 5 Vascularization after 12 weeks. After 12 weeks, further ingrowth of the surrounding tissue into the constructs occurred. Especially, a change in the vascularization (arrows) and the appearance of bigger fat cell aggregations $\left(^{*}\right)$ was noticed in all scaffolds. [Gp = Group, os-hMSCs = osteogenically stimulated hMSCs] Goldner's trichrome: scale bars: $200 \mu \mathrm{ms}$.

factor [25]. Consistently, improved angiogenesis after subcutaneous implantation of heparinized scaffolds loaded with VEGF was observed [3]. Further improvements could be achieved by developing prevascularized cell-matrixconstructs providing a sufficient nutrient supply at early stages after implantation [26]. Prevascularized constructs, allowing an early functioning metabolic cycle, were shown to improve the survival rate of osteoblasts in vivo compared to non-prevascularized constructs [27].

\section{Tissue}

The initiation of inflammatory processes by implantation of biological or synthetic materials is evident $[8,28,29]$. Essential parameters for the character and value of biological reaction are material properties and quality of the implanted foreign body [30]. Therefore, surface enlargement by means of interconnecting pores could be responsible for an increased invasion of reactive cells leading to foreign body reactions even in immunodeficient, athymic mice [31]. This might affect the survival of cells as a decrease of $\mathrm{pH}$ and release of degradation enzymes lead to changes in homoeostasis [30]. If and to which extent phagocytosis of human mesenchymal stem cells could take place in the course of such foreign body reactions remains unclear [32,33].
Development of granulation tissue was observable in all groups after 2 weeks in vivo. We suggest that this phenomenon is to be explained by the physiological tissue chronology during foreign body reactions [30]. The production of e.g. TNF $\alpha$ or EGF by macrophages is responsible for the initiation of neovascularization and proliferation of fibroblasts resulting in the formation of granulation tissue, which is replaced by permanent tissue afterwards. Consistent with previous results, a regression of granulation tissue was observed after 12 weeks in all groups [8].

No bone formation was observed in any of the scaffolds indicating an insufficient amount of osteoprogenitor cells as well as vascular supply. Low osteogenic capacity of the ectopic implantation site as well as missing osteoinductive properties of the scaffold must be assumed as possible reasons for our results [15]. Therefore, implantation of the scaffolds in orthotopic sites might improve bone formation by chemotactic agents. However, Kruyt et al. have already demonstrated no significant difference in cellbased bone formation between ectopic and orthotopic implantation [34].

The study is limited, beside the abovementioned shortcomings, especially by a small sample size. Therefore, 


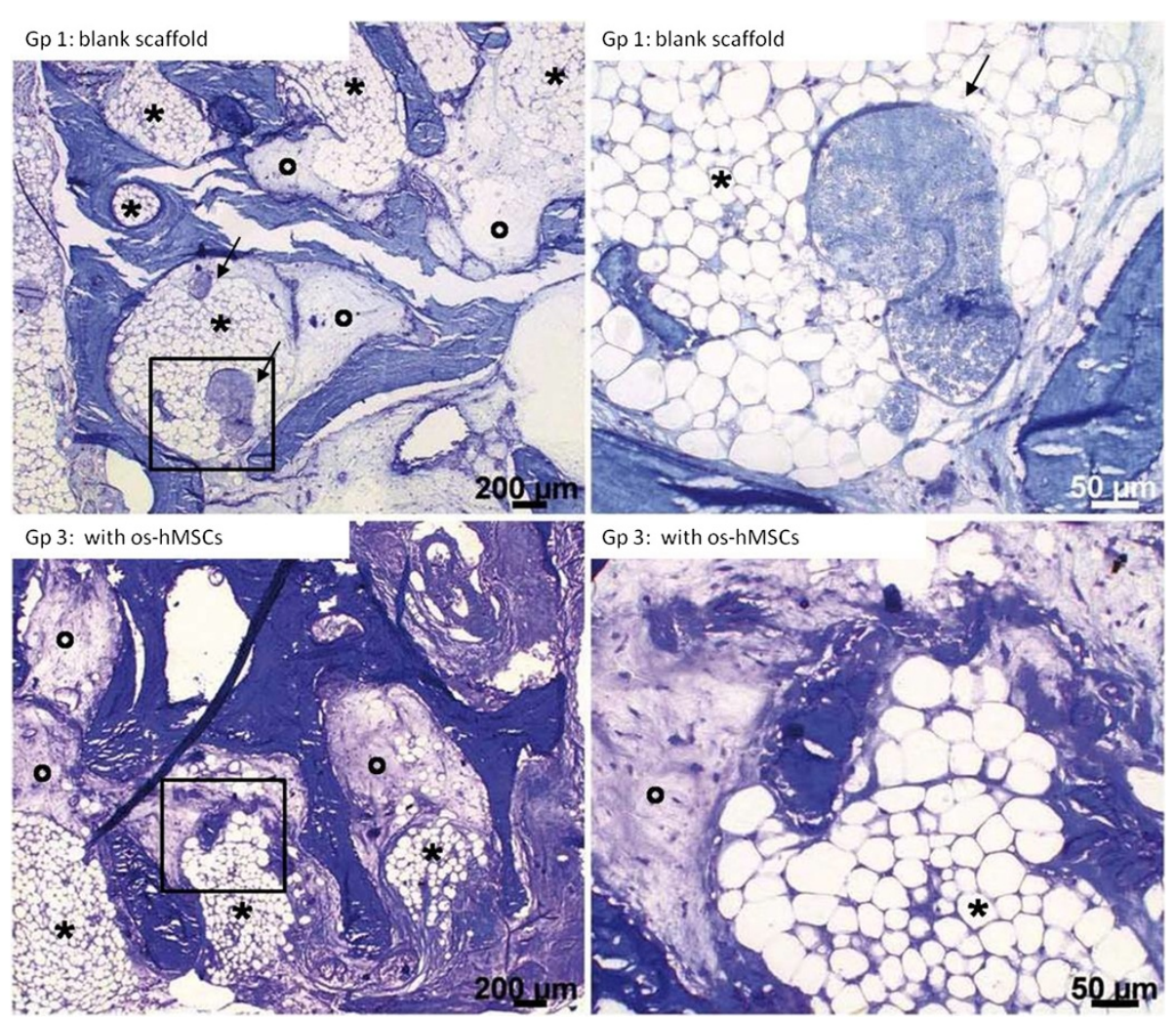

Figure 6 Tissue after 12 weeks. An increased expansion of fat cells $\left(^{*}\right)$ covering up to $60 \%$ of the scaffold surface and vessels (thin arrows) was found in all groups after 12 weeks in vivo implantation. Next to the fatty tissue, necrotic areas $\left(^{\circ}\right)$ were detectable in all groups. Pictures on the right side show the inserts in the left pictures. [Gp = Group, os-hMSCs = osteogenically stimulated hMSCs] Toluidine blue: scale bars: $200 \mu \mathrm{ms}$ (left), 50 ums (right).

further studies are needed to clarify if VEGF is capable of stimulating murine cells. Alternatively, the use of cocultures such as osteoblasts and endothelial cells could help to induce a sufficient blood supply in vivo and hence the new formation of bone.

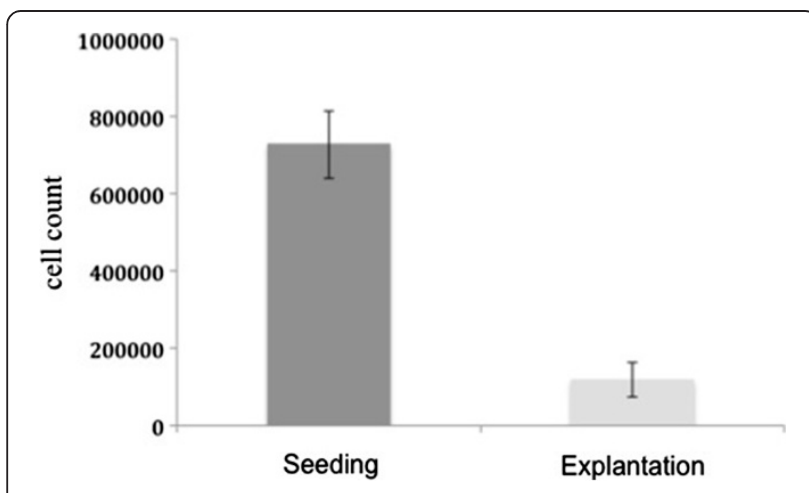

Figure 7 Cells on the scaffold. The number of cells on the scaffolds after explantation compared to the amount of initially seeded cells decreased in all groups.

\section{Conclusion}

Under the chosen prerequisites, VEGF treatment of osteogenically stimulated hMSCs loaded on cancellous bone scaffolds is not sufficient to enhance neovascularization, bone formation and/or improved cell survival. Human DNA can be found in inoculated scaffolds even

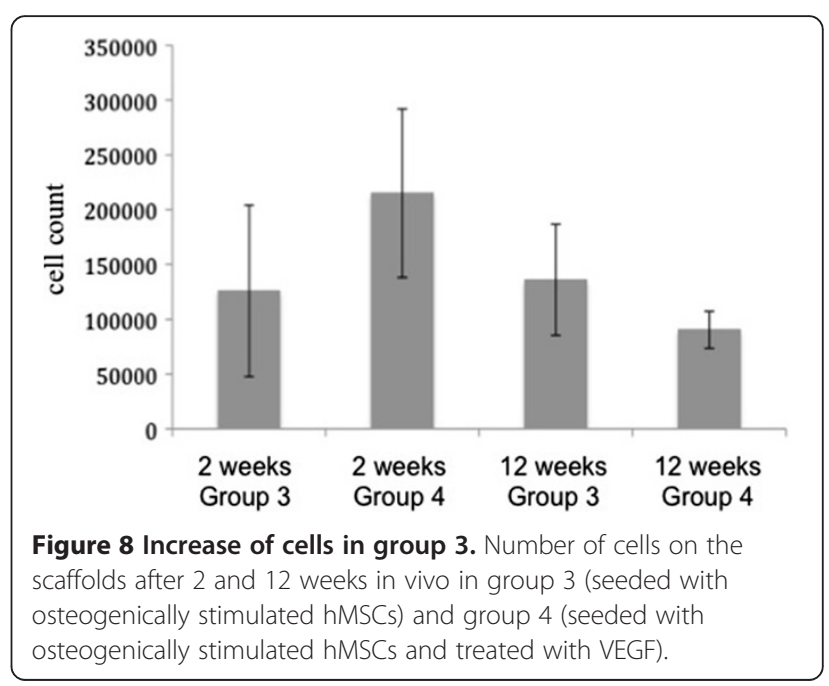


after 12 weeks in vivo but not in organs or the soft tissue surrounding following xenotransplantation.

\section{Additional file}

\section{Additional file 1: ARRIVE check list.}

\section{Abbrevations}

VEGF: Vascular Endothelial Growth Factor; hMSC: human Mesenchymal Stem Cells; EDTA: Ethylenediaminetetraacetic acid; CO2: Carbon dioxide; MSCGM: Mesenchymal Stem Cells Growth Medium; DMEM: Dubecco`s Modified Eagle Medium; FBS: Fetal Bovine Serum; MMA: Methyl Methacrylate; PBS: Phosphate Buffered Saline; DNA: Deoxyribonucleic acid; PCR: Polymerase Chain Reaction; SPSS: Statistical Package for the Social Sciences; BMSCs: Bone Marrow Stroma Cells; BMP-2: Bone Morphogenetic Protein-2; FGF-2: Fibroblast Growth Factor-2; pH: potential of hydrogen; TNFa: Tumor Necrosis Factor a; EGF: Epidermal Growth Factor.

\section{Competing interests}

The authors declare that they have no competing interests.

\section{Authors' contributions}

UL and FP were in charge of data acquisition, drafting and writing the manuscript and contributed to the conception of the study. SS, CE, SM and DD participated in the conception and design of the study, helped to draft the manuscript and gave substantive intellectual feedback on the manuscript. DD and MS contributed to the conception and the design of the study, the interpretation of data and gave intellectual feedback on the manuscript. All authors read and approved the final manuscript.

\section{Acknowledgement}

This work was supported by grants of the Bavarian Research Foundation (Collaboration for Tissue Engineering and Rapid Prototyping). We gratefully acknowledge Tutogen for providing the scaffolds (Tutobone) as well as Brigitte Hackl and Claudia Harbauer for their excellent technical assistance. This work contains data from the theses of UL and FP and is published with permission of the medical faculty of the LMU Munich. Furthermore, we thank Fritz Seidl, MA Interpreting and Translating, for his excellent language copyediting. The current address of Prof. Dr. Matthias Schieker is at Amgen GmbH, Munich, Germany.

\section{Author details \\ 'Laboratory of Experimental Surgery and Regenerative Medicine, Department of Surgery, University of Munich (LMU), Munich, Germany. ${ }^{2}$ Department of Orthopedics and Orthopedic Sports Medicine, Technical University of Munich (TU), Munich, Germany. ${ }^{3}$ Department of Trauma Surgery, Technical University of Munich (TU), Munich, Germany. ${ }^{4}$ Department of Orthopaedics, University Medical Center Hamburg-Eppendorf, Hamburg, Germany. ${ }^{5}$ Department of Restorative Dentistry \& Periodontology, University of Munich (LMU), Munich, Germany. ${ }^{6}$ Department of Anatomy, University of Munich (LMU), Munich, Germany.}

Received: 10 February 2014 Accepted: 23 September 2014 Published: 16 October 2014

\section{References}

1. Mikos $A G$, Sarakinos G, Lyman MD, Ingber DE, Vacanti JP, Langer R: Prevascularization of porous biodegradable polymers. Biotechnol Bioeng 1993, 42:716-723.

2. Santos MI, Reis RL: Vascularization in bone tissue engineering: physiology, current strategies, major hurdles and future challenges. Macromol Biosci 2010, 10:12-27.

3. Ferrara N, Gerber HP, LeCouter J: The biology of VEGF and its receptors. Nat Med 2003, 9:669-676.

4. Kaigler D, Wang Z, Horger K, Mooney DJ, Krebsbach PH: VEGF scaffolds enhance angiogenesis and bone regeneration in irradiated osseous defects. J Bone Miner Res 2006, 21:735-744.

5. Clarkin CE, Emery RJ, Pitsillides AA, Wheeler-Jones CP: Evaluation of VEGFmediated signaling in primary human cells reveals a paracrine action for
VEGF in osteoblast-mediated crosstalk to endothelial cells. J Cell Physiol 2008, 214:537-544

6. Grellier M, Granja PL, Fricain JC, Bidarra SJ, Renard M, Bareille R, Bourget C, Amedee J, Barbosa MA: The effect of the co-immobilization of human osteoprogenitors and endothelial cells within alginate microspheres on mineralization in a bone defect. Biomaterials 2009, 30:3271-3278.

7. Via AG, Frizziero A, Oliva F: Biological properties of mesenchymal Stem Cells from different sources. Muscles Ligaments Tendons J 2012, 2:154-162.

8. Seitz S, Ern K, Lamper G, Docheva D, Drosse I, Milz S, Mutschler W, Schieker M: Influence of in vitro cultivation on the integration of cell-matrix constructs after subcutaneous implantation. Tissue Eng 2007, 13:1059-1067.

9. van Gaalen SM, Dhert WJ, van den Muysenberg A, Oner FC, Van Blitterswijk C, Verbout AJ, De Bruijn JD: Bone tissue engineering for spine fusion: an experimental study on ectopic and orthotopic implants in rats. Tissue Eng 2004, 10:231-239.

10. Becker M, Nitsche A, Neumann C, Aumann J, Junghahn I, Fichtner I: Sensitive PCR method for the detection and real-time quantification of human cells in xenotransplantation systems. Br J Cancer 2002, 87:1328-1335

11. Docheva D, Popov C, Mutschler W, Schieker M: Human mesenchymal stem cells in contact with their environment: surface characteristics and the integrin system. J Cell Mol Med 2007, 11:21-38.

12. Mauney JR, Jaquiery C, Volloch V, Heberer M, Martin I, Kaplan DL: In vitro and in vivo evaluation of differentially demineralized cancellous bone scaffolds combined with human bone marrow stromal cells for tissue engineering. Biomaterials 2005, 26:3173-3185.

13. Bareille R, Lafage-Proust MH, Faucheux C, Laroche N, Wenz R, Dard M, Amedee $\mathrm{J}$ : Various evaluation techniques of newly formed bone in porous hydroxyapatite loaded with human bone marrow cells implanted in an extra-osseous site. Biomaterials 2000, 21:1345-1352.

14. Matsushima A, Kotobuki N, Tadokoro M, Kawate K, Yajima H, Takakura Y, Ohgushi $\mathrm{H}$ : In vivo osteogenic capability of human mesenchymal cells cultured on hydroxyapatite and on beta-tricalcium phosphate. Artif Organs 2009, 33:474-481.

15. Kruyt MC, de Bruijn JD, Wilson CE, Oner FC, van Blitterswijk CA, Verbout AJ Dhert WJ: Viable osteogenic cells are obligatory for tissue-engineered ectopic bone formation in goats. Tissue Eng 2003, 9:327-336.

16. Maegawa N, Kawamura K, Hirose M, Yajima H, Takakura Y, Ohgushi H: Enhancement of osteoblastic differentiation of mesenchymal stromal cells cultured by selective combination of bone morphogenetic protein2 (BMP-2) and fibroblast growth factor-2 (FGF-2). J Tissue Eng Regen Med 2007, 1:306-313.

17. Wang Y, Uemura T, Dong J, Kojima H, Tanaka J, Tateishi T: Application of perfusion culture system improves in vitro and in vivo osteogenesis of bone marrow-derived osteoblastic cells in porous ceramic materials. Tissue Eng 2003, 9:1205-1214.

18. Zilkens C, Logters T, Bittersohl B, Krauspe R, Lensing-Hohn S, Jager M: Spinning around or stagnation - what do osteoblasts and chondroblasts really like? Eur J Med Res 2010, 15:35-43.

19. Delaine-Smith RM, Reilly GC: Mesenchymal stem cell responses to mechanical stimuli. Muscles Ligaments Tendons J 2012, 2:169-180.

20. Volkmer E, Drosse I, Otto S, Stangelmayer A, Stengele M, Kallukalam BC, Mutschler W, Schieker M: Hypoxia in static and dynamic 3D culture systems for tissue engineering of bone. Tissue Eng Part A 2008, 14:1331-1340

21. Rouwkema J, Rivron NC, van Blitterswijk CA: Vascularization in tissue engineering. Trends Biotechnol 2008, 26:434-441.

22. Kruyt MC, Dhert WJ, Yuan H, Wilson CE, van Blitterswijk CA, Verbout AJ, de Bruijn JD: Bone tissue engineering in a critical size defect compared to ectopic implantations in the goat. J Orthop Res 2004, 22:544-551.

23. Potier E, Ferreira E, Meunier A, Sedel L, Logeart-Avramoglou D, Petite H: Prolonged hypoxia concomitant with serum deprivation induces massive human mesenchymal stem cell death. Tissue Eng 2007, 13:1325-1331.

24. Volkmer E, Kallukalam BC, Maertz J, Otto S, Drosse I, Polzer H, Bocker W, Stengele M, Docheva D, Mutschler W, Schieker M: Hypoxic preconditioning of human mesenchymal stem cells overcomes hypoxia-induced inhibition of osteogenic differentiation. Tissue Eng Part A 2010, 16:153-164.

25. Chen L, He Z, Chen B, Yang M, Zhao Y, Sun W, Xiao Z, Zhang J, Dai J: Loading of VEGF to the heparin cross-linked demineralized bone matrix improves vascularization of the scaffold. J Mater Sci Mater Med 2010, 21:309-317. 
26. Steffens $L$, Wenger $A$, Stark $G B$, Finkenzeller $G$ : In vivo engineering of a human vasculature for bone tissue engineering applications. I Cell Mol Med 2009, 13:3380-3386.

27. Arkudas A, Beier JP, Heidner K, Tjiawi J, Polykandriotis E, Srour S, Sturzl M, Horch RE, Kneser U: Axial prevascularization of porous matrices using an arteriovenous loop promotes survival and differentiation of transplanted autologous osteoblasts. Tissue Eng 2007, 13:1549-1560.

28. Yanagida H, Okada M, Masuda M, Ueki M, Narama I, Kitao S, Koyama Y, Furuzono T, Takakuda K: Cell adhesion and tissue response to hydroxyapatite nanocrystal-coated poly(L-lactic acid) fabric. J Biosci Bioeng 2009, 108:235-243.

29. Barbosa JN, Amaral IF, Aguas AP, Barbosa MA: Evaluation of the effect of the degree of acetylation on the inflammatory response to $3 \mathrm{D}$ porous chitosan scaffolds. J Biomed Mater Res A 2009, 93:20-28.

30. Anderson JM, Rodriguez A, Chang DT: Foreign body reaction to biomaterials. Semin Immunol 2008, 20:86-100.

31. Rodriguez A, Macewan SR, Meyerson H, Kirk JT, Anderson JM: The foreign body reaction in T-cell-deficient mice. J Biomed Mater Res A 2009, 90:106-113.

32. Xia Z, Ye H, Choong C, Ferguson DJ, Platt N, Cui Z, Triffitt JT: Macrophagic response to human mesenchymal stem cell and poly(epsiloncaprolactone) implantation in nonobese diabetic/severe combined immunodeficient mice. J Biomed Mater Res A 2004, 71:538-548.

33. Cabilly S, Gallily R: Non-immunological recognition and killing of xenogeneic cells by macrophages. II. Mechanism of killing. Immunology 1981, 44:357-365.

34. Kruyt MC, Dhert WJ, Oner FC, van Blitterswijk CA, Verbout AJ, de Bruijn JD: Analysis of ectopic and orthotopic bone formation in cell-based tissue-engineered constructs in goats. Biomaterials 2007, 28:1798-1805.

doi:10.1186/1471-2474-15-350

Cite this article as: Lenze et al:: Influence of osteogenic stimulation and VEGF treatment on in vivo bone formation in $\mathrm{hMSC}$-seeded cancellous bone scaffolds. BMC Musculoskeletal Disorders 2014 15:350.

\section{Submit your next manuscript to BioMed Central and take full advantage of:}

- Convenient online submission

- Thorough peer review

- No space constraints or color figure charges

- Immediate publication on acceptance

- Inclusion in PubMed, CAS, Scopus and Google Scholar

- Research which is freely available for redistribution

Submit your manuscript at www.biomedcentral.com/submit
C Biomed Central 